\title{
Interactive comment on "Spatio-temporal vegetation dynamics and relationship with climate over East Africa” by John Musau et al.
}

\section{John Musau et al.}

johnkuyega@gmail.com

Received and published: 29 March 2017

Dear Referee \#1, Thank you for your comments and positive feedback on our manuscript. Your comments have helped us to improve the quality of the manuscript. Please find attached a pdf file for our responses to all the comments. Best regards,

The authors

Please also note the supplement to this comment:

http://www.hydrol-earth-syst-sci-discuss.net/hess-2016-502/hess-2016-502-AC1supplement.pdf 